\title{
Reproductive System
}

National Cancer Institute

\section{Source}

National Cancer Institute. Reproductive System. NCI Thesaurus. Code C12841.

The org ans and tissues involved in the production and maturation of gametes and in their union and subsequent development as offspring. 